\title{
Healthy novel gluten-free formulations based on beans, carob fruit and rice: Extrusion effect on organic acids, tocopherols, phenolic compounds and bioactivity
}

\author{
Claudia Arribas $^{\mathrm{a}, \mathrm{b}}$, Eliana Pereira ${ }^{\mathrm{a}}$, Lillian Barros ${ }^{\mathrm{a}}$, Maria José Alves ${ }^{\mathrm{a}}$, Ricardo C. Calhelha ${ }^{\mathrm{a}}$, \\ Eva Guillamón $^{c}$, Mercedes M. Pedrosa ${ }^{\mathrm{b}}$, Isabel C.F.R. Ferreira ${ }^{\mathrm{a}, *}$ \\ ${ }^{a}$ Centro de Investigação de Montanha (CIMO), Instituto Politécnico de Bragança, Campus de Santa Apolónia, 5300-253 Bragança, Portugal \\ ${ }^{\mathrm{b}}$ Food Tecnhology Department, SGIT-INIA, Crta. De La Coruña, Km 7.5, 28040 Madrid, Spain \\ ${ }^{\mathrm{c}}$ Centre for the Food Quality, INIA, C/Universidad s/n, 42004 Soria, Spain
}

\section{A R T I C L E I N F O}

\section{Keywords:}

Bean/rice/carob fruit

Extrusion

Chemical composition

Phenolic profile

Bioactivity

\begin{abstract}
A B S T R A C T
Rice and legumes have great potential in the development of novel gluten-free snacks that are healthier than traditional snacks. Novel gluten-free extruded foods (composed of rice: $50-80 \%$, beans: $20-40 \%$ and carob: 5-10\%) were analysed and the extrusion effects regarding organic acids, tocopherols, phenolic compounds and bioactive properties were evaluated. The total concentration of organic acids was not significantly affected by extrusion, while tocopherols showed a significant reduction. Extrusion did not produce an increase of the total phenolic content. For the bioactivity assays, commercial extruded rice, carob and most of the extruded samples showed anti-proliferative activity, which was higher than in the non-extruded samples, while for the anti-inflammatory activity, the extrusion process did not show a significant effect. Regarding the antimicrobial activity, low potential was observed with extruded and non-extruded samples showing high values of MIC and MBC as the microorganisms tested were multi-resistant isolated clinical strains.
\end{abstract}

\section{Introduction}

Extrusion cooking technology is a high-temperature, short-time process, necessary to cause structural, physico-chemical and nutritional changes of raw materials, forcing the material to flow under different conditions (temperature, moisture, screw speed, and feed). Moreover, it is also a procedure characterised by automated control, high production capacity, continuous operation, high productivity and versatility, and it has high adaptability to processing conditions, energy efficiency, and low cost. This method is an important processing technique in the food industry, and it is considered an efficient manufacturing process (Alam, Kaur, Khaira, \& Gupta, 2016).

During the extrusion process, several reactions and structural changes can occur, which modify the flour properties through starch gelatinisation, the complex formation between amylose and lipids, degradation of pigments, Maillard browning, alterations in polyphenol content, inactivation of several anti-nutritional compounds (such as phytic acid, lectin, trypsin, chymotrypsin inhibitors and protein denaturation), texturisation and the improvement of sensory characteristics. These reactions represent a higher importance in the development of the structure and functionality of the end product. The extrusion process is a useful method in order to obtain products, such as expanded snack foods, ready-to-eat breakfast cereals, biscuits, modified starches, textured vegetable protein, pasta, meat substitutes and pet foods (Alam et al., 2016).

Currently, consumers demand gluten-free products that can improve their health and well-being. However, gluten-free products are usually nutritional- (low protein and fibre and high fat content) and phytochemical-deficient. White rice (Oryza sativa L.) has been reported as a good material for the development of extruded products (Alam et al., 2016); however, it does not contain many bioactive compounds since they are mainly located in the bran. Therefore, legumes offer an important alternative to the fortification of the de-husked rice, increasing the bioactive compounds content that have been partly removed during the rice processed, preventing damage associated to the deficiencies of micronutrients in rice-based diets.

Between pulses, dry beans (Phaseolus vulgaris L.) receive a great deal of attention for being a gluten-free, functional food that contains numerous phytochemicals endowed with useful biological activities. The consumption of this legume is associated with the risk reduction of

\footnotetext{
* Corresponding author.

E-mail address: iferreira@ipb.pt (I.C.F.R. Ferreira).
} 
chronic diseases, such as coronary heart disease, diabetes mellitus type II and obesity (Pedrosa et al., 2015 and cites herein). The carob fruit (Ceratonia siliqua L.) is a leguminous tree native to the Mediterranean region. This species is a source of soluble sugars, mainly sucrose, fructose and glucose, which leads to its use in sweets as a natural food additive and as a thickening agent (E-410, locust bean gum), but also as a stabiliser and flavouring agent. This species is also used for extracting sugars for making syrup or bioethanol, and carob fruit is mainly used for animal feed (Kotrotsios, Christaki, Bonos, Florou-Paneri, \& Spais, 2011). Carob flour is also a good source of dietary fibre, and it has been shown to have therapeutic potential for several diseases, including reducing low-density-lipoprotein cholesterol in hypercholesterolemic patients, regulating blood glucose levels, benefits for the body weight and improving digestion and lipid utilisation (Valero-Muntildoz, Martín-Fernández, Ballesteros, Lahera, \& de las Heras, 2014). Therefore, whole carob fruit flour could be a novel ingredient with great potential to be used for developing gluten-free, functional food products, such as extruded products.

Legumes also contain components such as organic acids and tocopherols, considered as bioactive components that may play healthy roles in consumers' lives (Pedrosa et al., 2015). These compounds have aroused much interest in the scientific community, triggering studies that demonstrate their effects on the health benefits related to the antihypertensive, antibacterial and antioxidant potential, and the protective effects in oxidative stress-induction, such as the carcinogenesis inhibitory effect (Xu \& Chang, 2010).

In previous studies (Arribas et al., 2017; Arribas, Cabellos, Cuadrado, Guillamón, \& Pedrosa, 2019), it has been reported that the extrusion of rice, pea and carob fruit blends enable the making of nutritious and phytochemical-rich food products that are suitable for establishing a healthy lifestyle. However, it has not been evaluated for the potential bioactivities, such as cytotoxicity, anti-inflammatory and antimicrobial. It has also not been evaluated for the extrusion effect on organic acids, tocopherols and the phenolic profile or for rice-based products enriched with beans and carob fruit.

Thus, considering the nutritional and economical aspects of beans and carob by fortifying rice with these flours, the hypothesis of developing a healthy gluten-free snack seems to be feasible. Therefore, in this study, six mixtures with different ratios of rice, beans and carob fruit were developed and the changes induced by extrusion-cooking of the organic acids, tocopherols content and phenolic profile, as well as evaluating the above mentioned bioactive properties. The results obtained were compared with raw materials and their non-extruded mixtures, i.e. commercial extruded rice, used as control.

\section{Materials and methods}

\subsection{Samples preparation}

White rice (Oryza sativa var. Montsianell) was commercially obtained from 'Cámara arrocera de Amposta' (Spain). The beans (Phaseolus vulgaris var. Almonga) were an improved and registered Spanish variety (NRVP 20064637 and \# TOV 002319) developed by ITACyL (Instituto Tecnológico Agrario de Castilla y León) and INIA (Instituto Nacional de Investigación y Tecnología Agraria y Alimentaria), and they were purchased from a local farmer Benjamín Rodríguez Alvarez, SL (León, Spain). Carob fruits (pods and seeds) (Ceratonia siliqua vars. Negreta and Roja) were supplied by 'Armengol Hermanos' (Spain).

Flours with different ratios of rice, beans and carob fruit were prepared in order to obtain six formulations. The different proportions of each flour were selected according to previous studies (Arribas et al., 2017; Varela et al., 2007) in order to obtain extrudates with adequate technical characteristics (expansion index and bulk density) (data not shown). The mixtures included calcium carbonate and salt to improve the texturisation and flavour, respectively (Table 1). The different
Table 1

Coded samples and the proportion of rice/bean/carob fruit flour formulations analysed.

\begin{tabular}{lllllll}
\hline & 20.1 & 20.2 & 20.3 & 40.1 & 40.2 & 40.3 \\
\hline Flours (\%) & & & & & & \\
Bean & 20 & 20 & 20 & 40 & 40 & 40 \\
Rice & 80 & 75 & 70 & 60 & 55 & 50 \\
Carob fruit & 0 & 5 & 10 & 0 & 5 & 10 \\
Additives (\%) & & & & & & \\
Salt & 0.5 & 0.75 & 1 & 1 & 1 & 1 \\
Calcium carbonate & 0.5 & 0.75 & 1 & 0.5 & 0.75 & 1 \\
\hline
\end{tabular}

mixtures were extruded at CARTIF (Valladolid, Spain) using a Clextral Evolum 25 twin-screw extruder (Clextral, Riez 42702 Firminy Cedez, France). The screw diameter (D) was $25 \mathrm{~mm}$ and the screw length (L) was $600 \mathrm{~mm}$, and a run capacity of $25 \mathrm{~kg}$ feed/h was used. The screw speed (Twin-screw volumetric feeder, Model LWFD5-20, K-Tron Corp., Pitman, NJ, USA) was $900-950 \mathrm{rpm}$, the temperature of extrusion was $120-130{ }^{\circ} \mathrm{C}$, and the water at a flow of $2.5-4 \mathrm{~kg} / \mathrm{h}$ was added. Extruded samples were dried with a convection air dryer $\left(85-120^{\circ} \mathrm{C}\right)$. Before chemical analysis, all the raw materials, extruded and non-extruded samples, were milled in a $1 \mathrm{~mm}$ sieve (Retsch SK1 mill, Hann, Germany) then stored in polyethylene bags until analysed.

Extruded samples were compared to a commercial rice-extruded sample, without legumes in the formulation, as control.

\subsection{Chemical composition of the raw, non-extruded and extruded materials}

\subsubsection{Determination of organic acids}

Organic acids were determined based on a protocol described by Dias et al. (2015). The organic acids were analysed using the Ultra Fast Liquid Chromatography (UFLC, Shimadzu 20A series, Kyoto, Japan) coupled with a photodiode array detector. The separation was achieved on a Sphere Clone reverse phase C18 column thermostatted at $35^{\circ} \mathrm{C}$. The results were expressed in $\mathrm{g}$ per $100 \mathrm{~g}$ of dry weight $(\mathrm{dw})$.

\subsubsection{Determination of tocopherols}

Tocopherols were determined according to the procedure previously described by Pereira, Barros, and Ferreira (2015) using an HPLC-Fluorescence (FP-2020, Jasco, Easton, MD, USA) programmed for excitation at $290 \mathrm{~nm}$ and emission at $330 \mathrm{~nm}$. The quantification was performed by comparison to the fluorescence signal obtained from the commercial standards ( $\alpha$-, $\beta-, \gamma$-, and $\delta$-isoforms) of each compound, and a racemic tocol (Matreya; Pleasant Gap, PA, USA) was used as the internal standard. The results were expressed in $\mu \mathrm{g}$ per $100 \mathrm{~g}$ of dw.

\subsubsection{Determination of phenolic compounds}

2.2.3.1. Extraction procedure. The extracts were obtained from the raw materials, extruded and non-extruded samples of rice and legumes. The samples were extracted with ethanol/water (80:20, v:v) according to Caleja et al. (2016). The alcoholic fraction of the extracts was evaporated in a rotary evaporator (rotary evaporator Büchi R-210) (at $40^{\circ} \mathrm{C}$ ) and the remaining aqueous fraction was purified using C18 SepPak $^{\circledR}$ Vac $3 \mathrm{cc}$ cartridge (Phenomenex, Torrance, CA, USA), following a procedure previously described by Guimarães et al. (2013). The obtained extracts were evaporated under reduced pressure $\left(40^{\circ} \mathrm{C}\right)$ in order to obtain a residue, which was further used to evaluate cytotoxicity, antimicrobial activity and the identification of phenolic compounds in concentrations of 8,20 , and $5 \mathrm{mg} / \mathrm{mL}$ respectively.

2.2.3.2. HPLC-DAD-ESI/MS analysis. The phenolic profile was determined following a procedure described by Bessada, Barreira, Barros, Ferreira, and Oliveira (2016) using the Dionex Ultimate 3000 UPLC (Thermo Scientific, San Jose, CA, USA). Data was collected 
simultaneously with a DAD (280 and $370 \mathrm{~nm}$ ) and in a mass spectrometer (Linear Ion Trap LTQ XL mass spectrometer, Thermo Finnigan, San Jose, CA, USA), operating in negative mode. Identification was based on the available standards and on literature data. Quantification was performed based on the UV-Vis signal, obtaining calibration curves for the available phenolic compounds standards (apigenin-6-C-glucoside, apigenin-7-O-glucoside, chlorogenic acid, ellagic acid, hesperetin, naringenin, $p$-coumaric acid, protocatechuic acid and quercetin-3-O-glucoside). In the case of unavailable commercial standards, the compounds were quantified via a calibration curve of the most similar standard available. The results were expressed as mg per $100 \mathrm{~g}$ of $\mathrm{dw}$.

\subsection{Bioactivity evaluation}

\subsubsection{Cytotoxicity}

This assay was tested using the purified extracts obtained from the methodology described in Section 2.2.3.1. and according to a procedure described by Guimarães et al. (2013). For anti-proliferative evaluation, four tumour cell lines were tested: HeLa (cervical carcinoma), HepG2 (hepatocellular carcinoma), MCF-7 (breast adenocarcinoma) and NCIH460 (non-small cell lung cancer). In order to know the cell growth inhibition, the methodology of the sulforhodamine B (SRB) assay was applied. For the hepatotoxicity evaluation, a freshly harvested porcine liver (PLP2), obtained from a local slaughterhouse, was used and the growth inhibition was also evaluated using the SRB assay following a procedure previously described by Guimarães et al. (2013). The results were expressed as $\mathrm{GI}_{50}(\mu \mathrm{g} / \mathrm{mL})$ (sample concentration that inhibited $50 \%$ of the cell growth), and ellipticine was used as positive control.

\subsubsection{Anti-inflammatory activity}

This analysis was performed using the purified extracts obtained from the methodology described in Section 2.2.3.1. This assay was developed according to the methodology of Correa et al. (2015). The mouse macrophage-like cell line RAW 264.7 stimulated with LPS was used in the assay, and dexamethasone $(50 \mu \mathrm{M})$ was applied as a positive control. Nitric oxide (NO) production was evaluated using the Griess Reagent System kit. The results were expressed as $\mathrm{EC}_{50}$ values $(\mu \mathrm{g} / \mathrm{mL})$ equal to the sample concentration providing $50 \%$ of inhibition of NO production.

\subsubsection{Antimicrobial activity}

The antimicrobial activity was analysed according to a study performed by Alves, Ferreira, Martins, and Pintado (2012) and using the purified extracts obtained from the methodology described in Section 2.2.3.1. The microorganisms used were multidrug resistant (MDR) and donated from the local health unit of Bragança and Hospital Centre of Trás-os-Montes and Alto-Douro-Vila Real, Northeast of Portugal; therefore, there was no direct contact with the patients. Gram-positive (MRSA [methicilin-resistant Staphylococcus aureus], MSSA [methicilinsensitive Staphylococcus aureus], Enterococcus faecalis and Listeria monocytogenes) and Gram-negative bacteria (Escherichia coli, Klebsiella pneumonia, Proteus mirabilis, Pseudomonas aeruginosa, and Morganella morganii) were used. The yeast Candida albicans was used in order to evaluate the antifungal activity. The minimum inhibitory concentration (MIC) was determined by the microdilution method. The minimal bactericidal concentrations (MBC) and minimal fungicide concentration (MFC) values were determined by sub-culturing the culture from each negative well and further incubated at $37^{\circ} \mathrm{C}$ for $24 \mathrm{~h}$. Three negative controls were prepared: one with Mueller-Hinton Broth (MHB)/Tryptic Soy Broth (TSB), another with the extract and the third one with medium and 5\% dimethyl sulfoxide (DMSO). The positive controls were prepared with MHB and each inoculum. Ampicillin, imipenem, vancomycin and fluconazole were used as positive controls.

\subsection{Statistical analysis}

All the analysis was performed in triplicate, and the data are presented as mean \pm standard deviation (SD). All the data were subjected to an analysis of variance (ANOVA) followed by Duncan's multiple range test using the Statgraphics Plus 5.1 computer package (Graphics Software System, Rockville, MD, USA.).

\section{Results and discussion}

\subsection{Organic acids and tocopherols composition}

The composition of organic acids in the rice-legumes blends extruded, non-extruded, and raw materials is presented in Table 2. Organic acids are biomolecules, indispensable for the human body, since they are essential intermediates in cell metabolism (Seabra et al., 2006). Generally, in all analysed samples, seven organic acids were identified, such as oxalic, quinic, malic, shikimic, succinic, citric and fumaric acids. The composition of these molecules in the studied samples was heterogeneous. The differences observed in the organic acids profile of the raw materials could be mainly due to the different rate of use of these compounds as respiratory substrates by the seeds (Lopez-Bucio, Nieto-Jacobo, Ramirez-Rodriguez, \& Herrera-Estrella, 2000). In general, citric acid, the major organic acid found in all samples except in raw rice and commercial extruded rice, ranges between 0.13 and $3.13 \mathrm{~g} / 100 \mathrm{~g} \mathrm{dw}$ in the N-Ex 20.2 and raw beans, respectively. Raw rice and carob fruit presented succinic and quinic acids as the major organic acids, respectively, and both have reported health benefits as antioxidants (Seabra et al., 2006). Moreover, in this study, all samples presented low content in oxalic acid, oscillating the values of raw materials between 0.032 to $0.161 \mathrm{~g} / 100 \mathrm{~g} \mathrm{dw}$, and the content in all the extruded samples was found in trace amounts or not detected (below the limit of detection (LOD)). Fumaric acid was also detected, but only in trace amounts in all the analysed samples. Considering the content in total organic acids, the bean sample was the raw material with the highest values $(3.46 \mathrm{~g} / 100 \mathrm{~g} \mathrm{dw})$. However, commercial extruded rice was the sample that showed the lowest organic acid content, presenting trace amounts of almost all the identified molecules. The changes in the studied samples, can be explained because the extrusion conditions used can affect the profile of organic acids. In this case, the conditions of temperature and shearing could have degraded the content of organic acids by the decarboxylation process during the extrusion process (Morales et al., 2015). Nevertheless, the total content of organic acids in other samples (Ex 20.1, Ex 40.1 and Ex 40.2) was not significantly affected by the food processing, which is in accordance with other reported works (Cámara, Diez, Torija, \& Cano, 1994). In general, the higher amount of legumes in the formulations, the higher concentration of organics acids.

Vegetables contain numerous phytochemicals, such as tocopherols, useful for their nutritional and nutraceutical properties. Tocopherols (constituents of vitamin E) appear in several active forms, presenting $\alpha$ tocopherol as the highest biological activity and $\gamma$-tocopherol as the most abundant in vegetable foods, such as sesame seed, soybean, black bean and peanut (Su, 1993). The effect of extrusion processing in the tocopherols profile is presented in Table 2. In general, all samples showed low levels of total tocopherols, ranging from 1.26 to $180 \mu \mathrm{g} /$ $100 \mathrm{gdw}$ (N-Ex 20.2 and raw beans, respectively). Carob fruit contained a 2.3 times lower concentration of total tocopherols $(79 \mu \mathrm{g} /$ $100 \mathrm{~g} \mathrm{dw}$ ) than raw beans. In some cases, particularly in extruded samples, the total absence of this vitamin was verified, except for Ex 40.2A and $\mathrm{Ex}$ 40.3A ( 7.40 and $20.37 \mu \mathrm{g} / 100 \mathrm{~g} \mathrm{dw}$, respectively). Morales et al. (2015) reported a significant decrease of the vitamin $\mathrm{E}$ content during the extrusion process of lentil samples. Notably, the stability and the sensibility of the fat-soluble vitamins, such as vitamin $\mathrm{E}$, depend on the food matrix composition, as well as the extrusion processing conditions used. According to Riaz, Asif, and Ali (2009), 


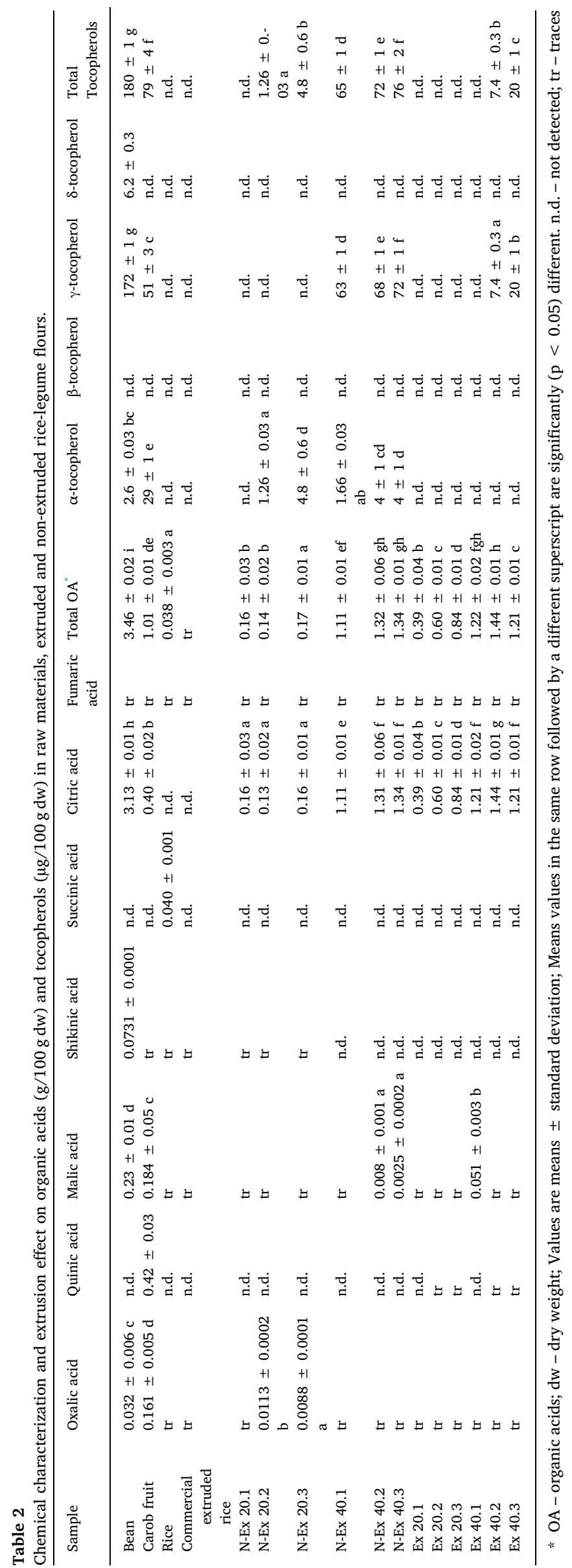

high temperature and moisture values promote the decrease of the $\alpha$ tocopherol and $\gamma$-tocopherol content, respectively. Vitamin E stability is also affected by lipid degradation because of thermal processing. Furthermore, a lower retention of the total of tocopherols in extruded amaranth, quinoa, kañiwa and lupine samples has been reported. The observed reduction on tocopherols (around 40-77\%) was positively related to high temperatures $\left(140-160^{\circ} \mathrm{C}\right)$ used during extrusion (Sundarrajan, 2014).

Regarding the vitamers detected ( $\alpha$-, $\gamma$ - and $\delta$-tocopherols), in general, the $\gamma$-tocopherol was the predominant isoform in all studied samples; such observation is in agreement with that reported for several legumes (soybean, chickpea, lentil, pea, common bean, broad bean, and three lupin sp.) (Boschin \& Arnoldi, 2011). Although these authors did not detect $\alpha$-tocopherol in the common bean, this vitamer was detected in the raw bean and unprocessed samples (N-Ex 20 and N-Ex 40) analysed in this study. The $\gamma$-tocopherol content of the carob fruit $(51.0 \mu \mathrm{g} /$ $100 \mathrm{~g} \mathrm{dw}$ ) was higher than that reported by Matthaus and Özcan (2011) for different cultivars of carob, with average values of approximately $29 \mu \mathrm{g} / 100 \mathrm{~g}$. After extrusion, there was a significant decrease in all the vitamin $\mathrm{E}$ isoforms, being $\gamma$-tocopherol the only vitamer detected. These results were similar to those reported for extruded formulations of lentil and nutritional yeast, as well as for extruded lentil flour fortified with different fibres (Ciudad-Mulero et al., 2018; Morales et al., 2015). The presence of vitamin $\mathrm{E}$ ( $\gamma$-tocopherol) in the extrudates could be of interest, since a great proportion of the population does not consume the recommended amount of vitamin E (Margier et al., 2018).

\subsection{Phenolic compounds composition}

Phenolic compounds were identified in the different raw materials and the extruded and non-extruded samples, and the tentative identification and quantification are presented in Tables $3 \mathrm{~A}$ and 3B. The bean, carob and extruded samples were composed of phenolic acids, flavonoids and hydrolysable tannins, while rice and commercial extruded rice did not reveal the presence of any phenolic compounds. Vichapong, Sookserm, Srijesdaruk, Swatsitang, and Srijaranai (2010) determined the phenolic composition in rice varieties, including pigment and non-pigment rice, and the results showed that the amount in pigment rice $(0.62-5.54 \mathrm{mg} / 100 \mathrm{~g} \mathrm{dw})$ was higher than in non-pigment rice $(0.15-2.41 \mathrm{mg} / 100 \mathrm{~g} \mathrm{dw})$. It is well known that bran is a rich source of phenolic compounds, and for that reason the raw rice without bran, as it is in the case of our study, normally showed low amounts or even an absence of phenolic compounds.

The raw bean sample revealed the presence of five phenolic compounds, such as one phenolic acid derivative and four flavonoids. Compound 5 (apigenin-7-O-glucoside) was positively identified considering the retention time, UV-Vis and fragmentation spectra of the commercial standard. The main compound in the raw bean samples was identified as $p$-coumaric acid derivative ([M-H $]^{-} m / z$ 387), representing $80 \%$ of the total content of the identified phenolic compounds. $p$-Coumaric acid is a hydroxycinnamic compound, present in many diets and is the most widely distributed phenolic component in plant tissues. Aguilera, Estrella, Benitez, Esteban, and Martín-Cabrejas (2011) identified a similar main compound in the dry bean variety Cannellini, which is a cream bean from Spain. Moreover, hydroxycinnamic compounds, such as $p$-coumaric, sinapic and ferulic acids were the main phenolic compounds identified in the Almonga bean variety (Pedrosa et al., 2015). Compound $2\left([\mathrm{M}-\mathrm{H}]^{-} \mathrm{m} / \mathrm{z}\right.$ 609) was identified as naringenin- $\mathrm{O}$-hexosyl-glucuronide. Naringenin derivatives were previously identified in bean samples var. Cannellini, Pinta and Curruquilla by Aguilera et al. (2011) and Pedrosa et al. (2015). These last authors reported a high difference between the varieties of Curruquilla and Almonga, which could explain the high variability of the phenolic compounds observed. Compound $3\left([\mathrm{M}-\mathrm{H}]^{-} m / z 415\right)$ released an $\mathrm{MS}^{2}$ fragment at $m / z 253$ ([M-H-162] $]^{-}$, loss of an hexosyl moiety), corresponding to a chrysin, thus being identified as chrysin- $O$ - 
Table 3A

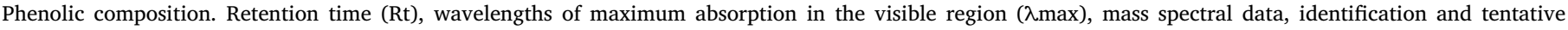
quantification (mg/100 $\mathrm{g} \mathrm{dw}$ ) of phenolic compounds in the raw bean and carob fruit samples.

\begin{tabular}{|c|c|c|c|c|c|c|}
\hline Peak & Rt (min) & $\lambda_{\max }(\mathrm{nm})$ & {$[\mathrm{M}-\mathrm{H}]^{-}(m / z)$} & $\mathrm{MS}^{2}$ & Tentative identification & $\begin{array}{l}\text { Quantification (mg/100 g } \\
\text { dw) }\end{array}$ \\
\hline \multicolumn{7}{|l|}{ Bean } \\
\hline 1 & 8.6 & 309 & 387 & 369 (22), 341 (17), 207 (100), 163 (72) & $p$-Coumanic acid derivative & $121 \pm 2$ \\
\hline 2 & 13.4 & 281,320 & 609 & $271(100)$ & $\begin{array}{l}\text { Naringenin-O-hexosyl- } \\
\text { glucuronide }\end{array}$ & $10 \pm 0.3$ \\
\hline 3 & 13.8 & 264,320 & 415 & $253(100)$ & Chrysin- $O$-hexoside & $5.3 \pm 0.2$ \\
\hline 4 & 18.8 & 330 & 655 & $\begin{array}{l}637 \text { (30),431 (100), } 413(60), 311(10), 298 \\
(4)\end{array}$ & Apigenin- $C$-hexoside derivative & $6.71 \pm 0.04$ \\
\hline 5 & 19.1 & 332 & 431 & $269(100)$ & $\begin{array}{l}\text { Apigenin-7-O-glucoside } \\
\text { Total phenolic compounds }\end{array}$ & $\begin{array}{l}8.86 \pm 0.02 \\
152 \pm 2\end{array}$ \\
\hline \multicolumn{7}{|c|}{ Carob } \\
\hline 6 & 5.2 & 269 & 443 & $\begin{array}{l}331 \text { (79), } 313 \text { (44), } 271 \text { (16), } 211 \text { (73), } 193 \\
(32), 169 \text { (85) }\end{array}$ & Galloyl-glucose derivative & $184.1 \pm 0.5$ \\
\hline 7 & 5.3 & 273 & 483 & $331(28), 313(23), 271(100), 211(6), 109(5)$ & Digalloyl-hexoside & $128 \pm 2$ \\
\hline 8 & 5.9 & 270 & 635 & $\begin{array}{l}483(17), 465 \text { (100), } 423(12), 331(9), 313 \\
(37), 271(3), 169(38)\end{array}$ & Trigalloyl-glucose & $94.9 \pm 0.6$ \\
\hline 9 & 6.9 & 276 & 595 & $\begin{array}{l}483(22), 443 \text { (78), } 331 \text { (17), } 313 \text { (9), } 211 \text { (4), } \\
169 \text { (73) }\end{array}$ & Digalloyl-glucose derivative & $281 \pm 4$ \\
\hline 10 & 8.9 & 278 & 635 & $\begin{array}{l}483(33), 465 \text { (93), } 423(3), 313(41), 271(5), \\
211 \text { (8), } 169 \text { (29) }\end{array}$ & Trigalloyl-glucose & $218.6 \pm 0.6$ \\
\hline 11 & 15.2 & 278 & 787 & $\begin{array}{l}635 \text { (18), } 617 \text { (77), } 465 \text { (30), } 447 \text { (6), } 313 \text { (4), } \\
169 \text { (16) }\end{array}$ & Tetragalloyl-glucose & $763 \pm 7$ \\
\hline 12 & 16.1 & 279 & 787 & $\begin{array}{l}635 \text { (18), } 617 \text { (77), } 465 \text { (30), } 447 \text { (6), } 313(4) \text {, } \\
169 \text { (16) }\end{array}$ & Tetragalloyl-glucose & $54.4 \pm 0.5$ \\
\hline 13 & 17.5 & 346 & 463 & $317(100)$ & Myricetin- $O$-pentoside & $91 \pm 3$ \\
\hline 14 & 18.7 & 360 & 301 & $\begin{array}{l}284 \text { (8), } 245 \text { (7), } 185 \text { (7), } 173 \text { (4)157 (3), } 145 \\
\text { (5) }\end{array}$ & Ellagic acid & $177 \pm 6$ \\
\hline 15 & 19.6 & 336 & 431 & $269(100)$ & Apigenin-7-O-glucoside & $26.2 \pm 0.5$ \\
\hline 16 & 20.1 & 270 & 939 & 787 (100), 635 (4), 617 (11), 465 (4) & Pentagalloyl-glucose & $34.8 \pm 0.5$ \\
\hline 17 & 20.4 & 350 & 463 & $301(100)$ & Quercetin-3-O-glucoside & $16.7 \pm 0.5$ \\
\hline 18 & 21.4 & 342 & 433 & $301(100)$ & Quercetin-O-pentoside & $12.31 \pm 0.03$ \\
\hline 19 & 21.5 & 345 & 433 & $301(100)$ & Quercetin-O-pentoside & $13.1 \pm 0.6$ \\
\hline 20 & 22.3 & 348 & 447 & $301(100)$ & Quercetin-3-O-rhamnoside & $118 \pm 5$ \\
\hline 21 & 23.3 & 342 & 447 & $301(100)$ & Quercetin-O-deoxyhexoside & $22.9 \pm 0.8$ \\
\hline 22 & 24.7 & 341 & 269 & $225(100)$ & Apigenin & $13.6 \pm 0.3$ \\
\hline 23 & 26.6 & 341 & 491 & $315(100)$ & Isorhamnetin-O-glucuronide & $11.0 \pm 0.5$ \\
\hline 24 & 27.0 & 348 & 431 & $285(100)$ & Kaempferol-O-deoxyhexoside & $10.5 \pm 0.4$ \\
\hline 25 & 27.7 & 358 & 461 & $315(100)$ & Isorhamnetin-O-deoxyhexoside & $10.5 \pm 0.1$ \\
\hline 26 & 32.0 & 350 & 285 & $\begin{array}{l}257 \text { (3), } 241 \text { (12), } 217 \text { (7), } 198 \text { (6), } 175 \text { (8), } \\
151 \text { (3) }\end{array}$ & Kaempferol & $20.9 \pm 0.3$ \\
\hline 27 & 33.0 & 360 & 315 & 301 (100), 271 (56), 255 (28), 151 (3) & Isorhamnetin & $14.8 \pm 0.5$ \\
\hline \multirow[t]{2}{*}{28} & 38.1 & 345 & 299 & $285(100)$ & Methylkaempferol & $13.6 \pm 0.5$ \\
\hline & $\begin{array}{l}\text { Total phenolic } \\
\text { compounds }\end{array}$ & $2332 \pm 5$ & & & & \\
\hline
\end{tabular}

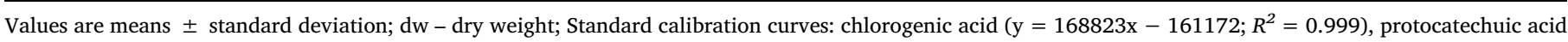

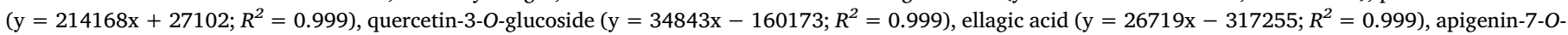

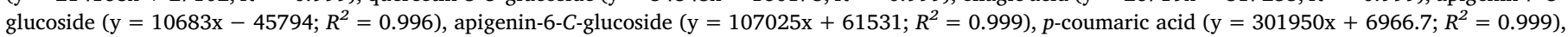
naringenin ( $\left.\mathrm{y}=18433 \mathrm{x}+78903 ; R^{2}=0.999\right)$.

hexoside. Compound $4\left([\mathrm{M}-\mathrm{H}]^{-} m / z\right.$ 655) revealed a similar fragmentation pattern to (iso)vitexin, thus bearing a $224 \mathrm{u}$ moiety, to which no consistent identity could be attributed, therefore it was identified as an apigenin- $C$-hexoside derivative. To the author's best knowledge, both these peaks were not previously described in the bean samples.

Carob fruit showed 23 phenolic compounds, one phenolic acid, eight hydrolysable tannins, and 14 flavonoids. Most of the compounds detected (peaks 6-21) were previously described by Rached et al. (2016) in a study with pods of $C$. siliqua collected from Sousse, Tunisia. The main phenolic compounds were gallotannins and quercetin derivatives, followed by other flavonoid glycoside derivatives, such as myricetin, kaempferol and isorhamnetin.

The main hydrolysable tannin was a tetragalloyl-glucoside (compound 11). Carob gallotannins have been gaining great attention in the food industry due to their significant antioxidant and antimicrobial activities (Buzzini et al., 2008). Rakib et al. (2010) identified 52 phenolic compounds in the ethanolic extract of carob from Marroco, and the main compounds were gallic acid, gallate glucoside and gallic acid glucoside. Gallotannins derivatives (peaks 6-12 and 16), identified in the raw carob, were composed by monomeric, dimeric, trimeric, tetrameric and pentameric galloyls linked to a glucose moiety. These compounds have been associated with important biological and pharmacological activities, such as antioxidant, anti-inflammatory and antiproliferative activities (Rached et al., 2016).

Ellagic acid (peak 14) was positively identified considering the retention time, UV-Vis and fragmentation spectra of the commercial standard. This phenolic acid has been reported to be an excellent antioxidant, having various cellular effects, including the inhibition of cancer cell proliferation (Boehning, Essien, Underwood, Dash, \& Boehning, 2018).

The remaining phenolic compounds (peaks 13 and 15-28) were identified as flavonoid derivatives and were also identified considering the findings reported by Papagiannopoulos, Wollseifen, Mellenthin, Haber, and Galensa (2004). These authors identified 41 phenolic compounds (mainly gallic acid and myricetin derivatives) in carob pods from Germany. Compound 21, identified as quercetin-O-deoxyhexoside, was the main flavonoid present in the samples, followed by myricetin-O-pentoside (compound 13). 
The different non-extruded formulations have a very similar phenolic profile (Table $3 \mathrm{~B})$. In general, the higher concentration of phenolic compounds was detected in the non-extruded blends with higher amounts of both legumes (bean and carob fruit) (N-Ex 40.3). In general, the phenolic profile in the N-Ex samples revealed the prevalence of the main phenolic acid identified in the raw bean (1) and the four main peaks of the raw carob $(11,13,14$, and 20$)$. Nevertheless, the extruded samples had in general lower concentration of phenolic compounds than their corresponding non-extruded counterparts. This could be due to the high temperature and pressure used during extrusion that may cause the decomposition of the thermos-labile phenolic compounds and may lead to the polymerisation of some polyphenols, such as tannins, during the extrusion process that could reduce their extractability (Ciudad-Mulero et al., 2018; Morales et al., 2015). Aguilera et al. (2011) and Pedrosa et al. (2015) also reported that a significant reduction of the phenolic content was verified in cooked and canned beans. Variations in different phenolic compounds were reported according to the plant material, the extrusion parameters and the phenolic compounds studied. So, Delgado-Licon et al. (2009) showed a significant reduction in the total phenols content during the extrusion process of mixtures composed by bean and corn flours; Arribas et al. (2019) reported an increase in the content of flavonols, but a decrease in the content of anthocyanins in the extruded rice, pea and carob flour formulations due to an increase in their extractability.

Taking into account the total phenolic content, the statistical analysis showed a significant difference between all samples, extruded and non-extruded, apart from the formulations with $40 \%$ beans and $60 \%$ rice (N-Ex 40.1 and Ex 40.1). In this case, the extrusion process did not cause relevant changes in the phenolic compounds content. On the other hand, the extruded samples with $20 \%$ beans and 0 or $5 \%$ carob were included in the same group by the statistical test, which indicated that by increasing the carob percentage above $5 \%$, the differences between the extruded formulations were accentuated.

\subsection{Bioactivity evaluation}

The results regarding the anti-proliferative activity using tumour and non-tumour cells are presented in Table 4. In general, raw bean and rice did not show anti-proliferative activity (cytotoxicity) in most of the studied cell lines, except for HepG2, where the raw rice showed moderated inhibition growth $\left(\mathrm{GI}_{50}=362 \mu \mathrm{g} / \mathrm{mL}\right)$. The commercial extruded rice and raw carob samples revealed activity in all tumour cell lines, with values ranging between $31 \mu \mathrm{g} / \mathrm{mL}$ for NCI-H460 and $274 \mu \mathrm{g} /$ $\mathrm{mL}$ for HepG2 for commercial extruded rice, and between $213 \mu \mathrm{g} / \mathrm{mL}$ and $308 \mu \mathrm{g} / \mathrm{mL}$ in HepG2 and NCI-H460 for carob. In contrast, raw carob was the only raw sample that showed hepatotoxicity activity (non-tumour cells; $359 \mu \mathrm{g} / \mathrm{mL}$ ), even though this value is above the concentrations necessary to inhibit the tumour cell lines (ranged between $213 \mu \mathrm{g} / \mathrm{mL}$ to $308 \mu \mathrm{g} / \mathrm{mL}$ in the carob fruit). According to Sobral et al. (2016), the inhibition of cell proliferation that occurred could be attributed to specific individual phenolic compounds, synergism/antagonism in the samples and/or to the presence of other compounds with a high anti-proliferative activity. The phenolic profile in the analysed carob sample revealed a high number of flavonoids and hydrolysable tannins, showing a positive correlation between the cytotoxicity of MCF7, NCI-H460 and HeLa cell lines and the phenolic content of the samples $\left(\mathrm{R}^{2}=0.8184, p=0.0038\right.$ and $\mathrm{R}^{2}=0.6228, p=0.023$ respectively).

It is well known that carob extracts have been used since ancient times in Arab and Chinese medicine, especially for mouth inflammations. The phenolic compounds, such as tetragalloyl glucoside (number 11 , Table 3B), mainly found in the samples that contained carob flour, have demonstrated anti-tumour activity (Zhang, Li, Kim, Hagerman, \& Lü, 2009). Tannins and flavonoids from carob pods have also shown anti-ulcer and gastroprotective properties (Rtibi et al., 2015). Therefore, taking into account the multiple biological activities of carob 
Table 4

Extrusion effect on cytotoxicity and anti-inflammatory potential of raw materials, extruded and non-extruded rice-legume flours.

\begin{tabular}{|c|c|c|c|c|c|c|}
\hline & \multicolumn{4}{|c|}{ Cytotoxicity (tumour cell lines) } & \multirow{2}{*}{$\begin{array}{l}\text { Hepatotoxicity (non-tumour cells) } \\
\mathrm{GI}_{50}(\mu \mathrm{g} / \mathrm{mL})\end{array}$} & \multirow{2}{*}{$\begin{array}{l}\text { Anti-inflammatory activity } \\
\mathrm{EC}_{50}(\mu \mathrm{g} / \mathrm{mL})\end{array}$} \\
\hline & $\mathrm{GI}_{50}(\mu \mathrm{g} / \mathrm{mL})$ & & & & & \\
\hline Sample & MCF-7 & NCI-H460 & HeLa & HepG2 & PLP2 & Nitric oxide (NO) production \\
\hline Bean & $>400$ & $>400$ & $>400$ & $>400$ & $>400$ & $>400$ \\
\hline Carob & $249 \pm 11 c$ & $308 \pm 15 \mathrm{~h}$ & $233 \pm 7 \mathrm{~g}$ & $213 \pm 6 \mathrm{efg}$ & $359 \pm 13 b$ & $286 \pm 11 \mathrm{c}$ \\
\hline Rice & $>400$ & $>400$ & $>400$ & $362 \pm 22 \mathrm{k}$ & $>400$ & $>400$ \\
\hline Commercial extruded rice & $207 \pm 9 b$ & $31 \pm 1 \mathrm{a}$ & $207 \pm 4$ ef & $274 \pm 16 \mathrm{i}$ & $>400$ & $>400$ \\
\hline N-Ex 20.1 & $196 \pm 6 a b$ & $206 \pm 9$ ef & $90 \pm 2 a$ & $115 \pm 7 \mathrm{a}$ & $279 \pm 11 \mathrm{ab}$ & $208 \pm 5 \mathrm{ab}$ \\
\hline N-Ex 20.2 & $>400$ & $183 \pm 8 \mathrm{de}$ & $133 \pm 1 b$ & $>400$ & $>400$ & $215 \pm 11 \mathrm{ab}$ \\
\hline N-Ex 20.3 & $>400$ & $161 \pm 7 d$ & $198 \pm 14 \mathrm{e}$ & $240 \pm 14 \mathrm{gh}$ & $>400$ & $212 \pm 4 \mathrm{ab}$ \\
\hline N-Ex 40.1 & $201 \pm 7 a b$ & $90 \pm 4 \mathrm{e}$ & $160 \pm 11 d$ & $129 \pm 8 \mathrm{ab}$ & $296 \pm 12 a b$ & $207 \pm 18 \mathrm{ab}$ \\
\hline N-Ex 40.2 & $>400$ & $>400$ & $223 \pm 1 \mathrm{f}$ & $>400$ & $>400$ & $301 \pm 19 c$ \\
\hline N-Ex 40.3 & $>400$ & $115 \pm 5$ & $202 \pm 14 \mathrm{e}$ & $308 \pm 18 \mathrm{j}$ & $>400$ & $>400$ \\
\hline Ex 20.1 & $197 \pm 7 a b$ & $170 \pm 10 d$ & $174 \pm 1 d$ & $202 \pm 12$ ef & $264 \pm 10 a b$ & $194 \pm 10 a$ \\
\hline Ex 20.2 & $200 \pm 7 \mathrm{ab}$ & $174 \pm 10 \mathrm{~d}$ & $199 \pm 4 \mathrm{e}$ & $164 \pm 10 \mathrm{~cd}$ & $215 \pm 61 \mathrm{a}$ & $>400$ \\
\hline Ex 20.3 & $188 \pm 11 \mathrm{a}$ & $198 \pm 13 \mathrm{e}$ & $157 \pm 1 \mathrm{~cd}$ & $148 \pm 9 b c$ & $272 \pm 10 \mathrm{ab}$ & $>400$ \\
\hline Ex 40.1 & $213 \pm 11 b$ & $198 \pm 13 b$ & $123 \pm 2 b$ & $187 \pm 12 \mathrm{de}$ & $222 \pm 62 \mathrm{a}$ & $226 \pm 16 b$ \\
\hline Ex 40.2 & $188 \pm 6 a$ & $221 \pm 15 \mathrm{fg}$ & $140 \pm 14 b c$ & $251 \pm 15 \mathrm{hi}$ & $207 \pm 81 \mathrm{a}$ & $>400$ \\
\hline Ex 40.3 & $169 \pm 11 b$ & $233 \pm 8 \mathrm{cg}$ & $212 \pm 2 d$ & $219 \pm 14 \mathrm{fg}$ & $330 \pm 16 b$ & $200 \pm 2 a b$ \\
\hline
\end{tabular}

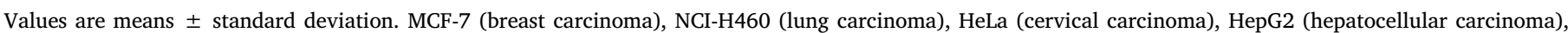

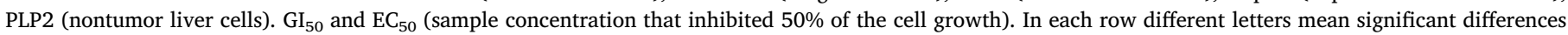

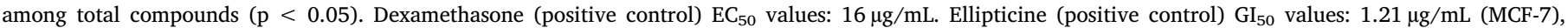
$1.03 \mu \mathrm{g} / \mathrm{mL}$ (NCI-H460), $0.91 \mu \mathrm{g} / \mathrm{mL}$ (HeLa), $1.10 \mu \mathrm{g} / \mathrm{mL}$ (HepG2) and 2.29 $\mu \mathrm{g} / \mathrm{mL}$ (PLP2).

phenolic compounds, the samples formulated with carob could have great potential in the prevention of several diseases.

In general, the results obtained in the extruded samples (Ex) also exhibited anti-proliferative potential, ranging from $169-213 \mu \mathrm{g} / \mathrm{mL}$ for MCF-7, $170-233 \mu \mathrm{g} / \mathrm{mL}$ for NCI-H460, $123-212 \mu \mathrm{g} / \mathrm{mL}$ for HeLa, and $148-251 \mu \mathrm{g} / \mathrm{mL}$ for HepG2. Nonetheless, in this assay, there were some samples (N-Ex 20.2, N-Ex 20.3, N-Ex 40.2 and N-Ex 40.3) that did not show anti-proliferative capacity in some of the tested tumour cell lines.

Considering the results for hepatotoxicity (non-tumour porcine liver cell line) the samples N-Ex with carob in their formulation presented low hepatotoxicity showing the highest $\mathrm{GI}_{50}$ value. The N-Ex 20.1, N-Ex 40.1 and the extruded samples presented toxicity, and the $\mathrm{GI}_{50}$ values varied between $215 \mu \mathrm{g} / \mathrm{mL}$ and $330 \mu \mathrm{g} / \mathrm{mL}$ in Ex 20.2 and Ex 40.3 samples, respectively. Nonetheless, the hepatotoxicity values were always higher than the $\mathrm{GI}_{50}$ concentrations obtained for the tumour cell lines.

In general, we can conclude that the extrusion process improves the cytotoxic potential in the sample mixture of rice-legumes, because they revealed lower $\mathrm{GI}_{50}$ concentrations after the extrusion process.

The anti-inflammatory activity results obtained for the studied samples are present in Table 4. In this assay a high heterogeneity of the results was observed, in which several samples such as raw bean, rice, commercial extruded rice, N-Ex 40.3, Ex 20.2, Ex 20.3, and Ex 40.2, revealed no anti-inflammatory activity. Samples N-Ex 20.1, N-Ex 20.2, N-Ex 20.3, N-Ex 40.1, N-Ex 40.2, Ex 20.1, Ex 40.1 and Ex 40.3 showed anti-inflammatory capacity, with $\mathrm{EC}_{50}$ values ranging from 194 to $301 \mu \mathrm{g} / \mathrm{mL}$ (for Ex 20.1 and N-Ex 40.2, respectively). Nevertheless, in general, the non-extruded samples with bean and carob (except N-Ex 40.3) had a higher anti-inflammatory activity than the extruded samples; thus, the extrusion process reduced the anti-inflammatory capacity of the samples, except in the samples without carob (Ex 20.1 and Ex 40.1). This reduction could be related to the lower phenolic content detected in the extruded samples (Table 3B) although statistical analysis showed that the increase of legumes in the formulation does not improve the anti-inflammatory activity of the sample. This can be due to an antagonistic effect between the phenolic compounds provided by the beans and carob (Sobral et al., 2016) and/or the presence and amount of other bioactive compounds (Alam et al., 2016). Other authors showed the great potential of different Phaseolus angularis varieties as anti-inflammatory due to their target transcription factors and inflammatory enzymes (Yu et al., 2011). Montoya-Rodríguez, MilánCarrillo, Reyes-Moreno, and de Mejía (2015) reported that the antiinflammatory activity of amaranth hydrolysates was improved due to the production of bioactive peptides during the extrusion process. Moreover, the extrusion conditions (temperature, moisture and pressure) used can highly affect the bioactivities of the extrudates. This would be due to an increase in the antioxidant activity, mainly through the production of different pigments (melanoidins) and Maillard compounds during extrusion (Ciudad-Mulero et al., 2018). According to Alves et al. (2016), the bioactive characteristics of legumes can also be affected by the storage time and degree of protein hydrolysis during the extrusion process. They showed that although little is known about the postharvest effect of storage regarding anti-inflammatory potential, samples stored for zero, three and six months did not significantly affect the bioactive activity of pancreatin hydrolysates of Carioca bean $(P$. vulgaris). In our case, the samples had been stored for a higher period (12 months), therefore the anti-inflammatory potential of these samples could have been affected by these conditions.

Le Marchand (2002) reported that some flavonoids showed antiinflammatory activity using in vitro assays and in animal model assays. According to Zhu, Du, and Xu (2018), legumes contain a high level of phytochemicals, such as phenolic acids, flavonols, isoflavones, anthocyanins and condensed tannins, which show anti-inflammatory effects. In a previous study, extracts from beans (pinto and black) showed antiproliferation capacities against human gastric and colorectal cancer cells (Xu \& Chang, 2010). Lachkar et al. (2016) showed the effect of different concentrations of methanolic extract of raw carob in an antiinflammatory assay using rats, and the results obtained suggest that the methanolic extract of $C$. siliqua had significant anti-inflammatory activity associated with some molecular targets of pro-inflammatory mediators like serotonin, histamine or cytokine in inflammatory responses, mainly due to the presence of phenolic compounds with significant antioxidant, anti-inflammatory and redox properties. Rtibi et al. (2015) reported that a carob pod aqueous extract, rich in tannins and flavonoids, also showed anti-inflammatory properties. In addition, raw rice and beans did not show cytotoxic or anti-inflammatory activities; however, carob presented the potential to inhibit the growth of all the studied tumour cell lines, as well as anti-inflammatory activity.

The results of antibacterial and antifungal activities are presented in Table 5. All samples presented very low MIC values (values ranging 
Table 5

Antimicrobial activity of the raw materials, extruded and non-extruded rice-legume flours (MIC, MBC and MFC, mg/mL).

\begin{tabular}{|c|c|c|c|c|c|c|c|c|c|c|c|}
\hline \multirow[b]{2}{*}{ Sample } & & \multicolumn{5}{|c|}{ Gram-negative bacteria } & \multicolumn{4}{|c|}{ Gram-positive bacteria } & \multirow{2}{*}{$\begin{array}{l}\text { Yeasts } \\
\text { C.a. }\end{array}$} \\
\hline & & E.c. & K.p. & M.m. & P.m. & P.a. & E.f. & L.m. & MRSA & MSSA & \\
\hline \multirow[t]{2}{*}{ Bean } & MIC & $>20$ & $>20$ & $>20$ & $>20$ & $>20$ & $>20$ & $>20$ & $>20$ & $>20$ & $>20$ \\
\hline & MBC & $>20$ & $>20$ & $>20$ & $>20$ & $>20$ & $>20$ & $>20$ & $>20$ & $>20$ & $>20$ \\
\hline \multirow[t]{2}{*}{ Carob } & MIC & $>20$ & $>20$ & $>20$ & $>20$ & $>20$ & $>20$ & $>20$ & $>20$ & $>20$ & $>20$ \\
\hline & MBC & $>20$ & $>20$ & $>20$ & $>20$ & $>20$ & $>20$ & $>20$ & $>20$ & $>20$ & $>20$ \\
\hline \multirow[t]{2}{*}{ Rice } & MIC & $>20$ & $>20$ & $>20$ & $>20$ & $>20$ & $>20$ & $>20$ & $>20$ & $>20$ & $>20$ \\
\hline & MBC & $>20$ & $>20$ & $>20$ & $>20$ & $>20$ & $>20$ & $>20$ & $>20$ & $>20$ & $>20$ \\
\hline \multirow[t]{2}{*}{ Commercial extruded rice } & MIC & $>20$ & $>20$ & $>20$ & $>20$ & $>20$ & $>20$ & $>20$ & $>20$ & $>20$ & $>20$ \\
\hline & MBC & $>20$ & $>20$ & $>20$ & $>20$ & $>20$ & $>20$ & $>20$ & $>20$ & $>20$ & $>20$ \\
\hline \multirow[t]{2}{*}{ N-Ex 20.1} & MIC & $>20$ & $>20$ & $>20$ & $>20$ & $>20$ & 20 & $>20$ & $>20$ & $>20$ & $>20$ \\
\hline & MBC & $>20$ & $>20$ & $>20$ & $>20$ & $>20$ & $>20$ & $>20$ & $>20$ & $>20$ & $>20$ \\
\hline \multirow[t]{2}{*}{ N-Ex 20.2} & MIC & $>20$ & $>20$ & $>20$ & $>20$ & $>20$ & 20 & $>20$ & $>20$ & $>20$ & $>20$ \\
\hline & $\mathrm{MBC}$ & $>20$ & $>20$ & $>20$ & $>20$ & $>20$ & $>20$ & $>20$ & $>20$ & $>20$ & $>20$ \\
\hline \multirow[t]{2}{*}{ N-Ex 20.3} & MIC & $>20$ & $>20$ & $>20$ & $>20$ & $>20$ & $>20$ & $>20$ & $>20$ & $>20$ & $>20$ \\
\hline & MBC & $>20$ & $>20$ & $>20$ & $>20$ & $>20$ & $>20$ & $>20$ & $>20$ & $>20$ & $>20$ \\
\hline \multirow[t]{2}{*}{ N-Ex 40.1} & MIC & $>20$ & $>20$ & $>20$ & $>20$ & $>20$ & $>20$ & $>20$ & $>20$ & $>20$ & 20 \\
\hline & MBC & $>20$ & $>20$ & $>20$ & $>20$ & $>20$ & $>20$ & $>20$ & $>20$ & $>20$ & $>20$ \\
\hline \multirow[t]{2}{*}{ N-Ex 40.2} & MIC & $>20$ & $>20$ & $>20$ & $>20$ & $>20$ & 20 & $>20$ & $>20$ & $>20$ & $>20$ \\
\hline & MBC & $>20$ & $>20$ & $>20$ & $>20$ & $>20$ & $>20$ & $>20$ & $>20$ & $>20$ & $>20$ \\
\hline \multirow[t]{2}{*}{ N-Ex40.3 } & MIC & $>20$ & $>20$ & $>20$ & $>20$ & $>20$ & 20 & $>20$ & 20 & $>20$ & 20 \\
\hline & MBC & $>20$ & $>20$ & $>20$ & $>20$ & $>20$ & $>20$ & $>20$ & $>20$ & $>20$ & $>20$ \\
\hline \multirow[t]{2}{*}{ Ex 20.1} & MIC & $>20$ & $>20$ & $>20$ & $>20$ & $>20$ & $>20$ & $>20$ & $>20$ & $>20$ & $>20$ \\
\hline & MBC & $>20$ & $>20$ & $>20$ & $>20$ & $>20$ & $>20$ & $>20$ & $>20$ & $>20$ & $>20$ \\
\hline \multirow[t]{2}{*}{ Ex 20.2} & MIC & $>20$ & $>20$ & $>20$ & $>20$ & $>20$ & 20 & $>20$ & $>20$ & $>20$ & 20 \\
\hline & MBC & $>20$ & $>20$ & $>20$ & $>20$ & $>20$ & $>20$ & $>20$ & $>20$ & $>20$ & $>20$ \\
\hline \multirow[t]{2}{*}{ Ex 20.3} & MIC & 20 & 20 & 20 & 20 & $>20$ & 10 & 20 & 20 & 10 & $>20$ \\
\hline & MBC & $>20$ & $>20$ & $>20$ & $>20$ & $>20$ & $>20$ & $>20$ & $>20$ & $>20$ & $>20$ \\
\hline \multirow[t]{2}{*}{ Ex 40.1} & MIC & $>20$ & $>20$ & $>20$ & $>20$ & $>20$ & $>20$ & $>20$ & $>20$ & $>20$ & $>20$ \\
\hline & MBC & $>20$ & $>20$ & $>20$ & $>20$ & $>20$ & $>20$ & $>20$ & $>20$ & $>20$ & $>20$ \\
\hline \multirow[t]{2}{*}{ Ex 40.2} & MIC & $>20$ & $>20$ & $>20$ & $>20$ & $>20$ & $>20$ & $>20$ & $>20$ & $>20$ & $>20$ \\
\hline & MBC & $>20$ & $>20$ & $>20$ & $>20$ & $>20$ & $>20$ & $>20$ & $>20$ & $>20$ & $>20$ \\
\hline \multirow[t]{2}{*}{ Ex 40.3} & MIC & $>20$ & $>20$ & $>20$ & $>20$ & $>20$ & $>20$ & $>20$ & $>20$ & $>20$ & $>20$ \\
\hline & MBC & $>20$ & $>20$ & $>20$ & $>20$ & $>20$ & $>20$ & $>20$ & $>20$ & $>20$ & $>20$ \\
\hline \multirow[t]{2}{*}{ Ampicillin $(20 \mathrm{mg} / \mathrm{mL})$} & MIC & $<0.15$ & 10 & 20 & $<0.15$ & $>20$ & $<0.15$ & $<0.15$ & $<0.15$ & $<0.15$ & n.t. \\
\hline & MBC & & 20 & $>20$ & & & & & & & \\
\hline \multirow[t]{2}{*}{ Imipenem $(1 \mathrm{mg} / \mathrm{mL})$} & MIC & $<0.0078$ & $<0.0078$ & $<0.0078$ & $<0.0078$ & 0.5 & n.t. & $<0.0078$ & n.t. & n.t. & n.t. \\
\hline & MBC & & & & & 1.0 & & & & & \\
\hline Vancomycin $(1 \mathrm{mg} / \mathrm{mL})$ & MIC & n.t. & n.t. & n.t. & n.t. & n.t. & $<0.0078$ & n.t. & 0.25 & 0.25 & n.t. \\
\hline & MBC & & & & & & & & 0.5 & 0.5 & \\
\hline Fluconazole ( $1 \mathrm{mg} / \mathrm{mL})$ & MIC & n.t. & n.t. & n.t. & n.t. & n.t. & n.t. & n.t. & n.t. & n.t. & 0.06 \\
\hline & MFC & & & & & & & & & & \\
\hline
\end{tabular}

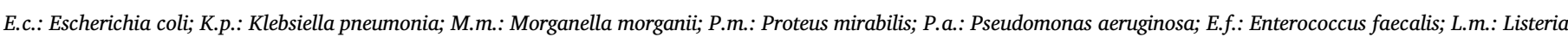

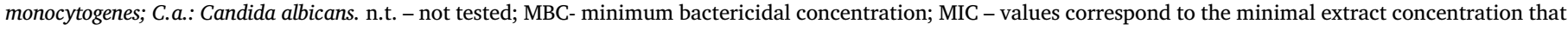

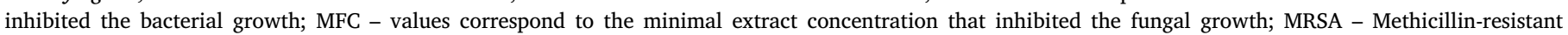
Staphylococcus aureus; MSSA - Methicillin-sensitive Staphylococcus aureus.

between 10 and $20 \mathrm{mg} / \mathrm{mL}$ ) and the absence of MBC and MFC ( $>20 \mathrm{mg} / \mathrm{mL}$ ). The raw materials all showed concentrations higher than $20 \mathrm{mg} / \mathrm{mL}$ for the tested microorganisms. According to the results, it was observed that the sample Ex 20.3 presented the highest MIC values for almost all Gram-negative and Gram-positive bacteria strains. This extruded sampled revealed the best antimicrobial activity for $E$. faecalis and MSSA (MIC values of $10 \mathrm{mg} / \mathrm{mL}$ ). The strain that revealed a higher sensitivity in several extruded and non-extruded samples (N-Ex 20.1, N-Ex 20.2, Ex 20.2, Ex 20.3, N-Ex 40.2 and N-Ex 40.3) was E. faecalis (E.f.) showing MIC values of $20 \mathrm{mg} / \mathrm{mL}$. Regarding the antifungal activity, using a C. albicans strain (C.a.), the low antifungal potential of the studied extracts was evident. In raw samples and in most of the extruded and non-extruded samples, no antifungal activity was observed (MIC/MFC > $20 \mathrm{mg} / \mathrm{mL}$ ). However, Ex 20.2, N-Ex 40.1 and N-Ex 40.3 samples revealed MIC values of $20 \mathrm{mg} / \mathrm{mL}$.

The results of this study agreed with Sammour and Abd-El-Raheem El- Shanshoury (1992), which reported that several ethanolic extracts of different legumes seeds had no antimicrobial activity. In another study performed by Amarowicz, Dykes, and Pegg (2008), the tannin fraction of an acetone extract of red beans showed high levels of activity $(62.5-125 \mu \mathrm{g} / \mathrm{mL})$ against Listeria monocytogenes. Nonetheless, the tested strains corresponded to ATCC, which are more sensitive microorganisms than the herein studied multi-resistant clinical isolates. Kondo, Teongtip, Srichana, and Itharat (2015) studied the antimicrobial activity of rice bran and the results showed that MIC values ranged between 7.81 and $31.25 \mathrm{mg} / \mathrm{mL}$ in most used strains, not including Vibrio cholerae and $S$. aureus. The oil, plant sterols, tocopherols, oryzanol and $\beta$-sitosterol present in the rice bran are mainly related to the antimicrobial potential of rice. For this reason, in general, the results of MIC and $\mathrm{MBC}$ obtained in the white rice raw material, without bran, and in the extruded and non-extruded mixtures had values around $20 \mathrm{mg} / \mathrm{mL}$ due to the high percentage of white rice (values of $50-80 \%$ in all these samples).

In general, Ex-20.3 (10\% of carob) was the sample that showed the best inhibitory growth potential. The combination of the phenolic compounds present in the sample of carob and bean can justify the MIC values obtained for Ex-20.3A. This higher potential can also be explained because the extrusion process may increase the products formed during the Maillard reaction, enhancing the antimicrobial potential. Nevertheless, this processing method can also cause chemical changes, such as alteration in the molecular structure of bioactive compounds (e.g. phenolic compounds), followed by a reduction of their biochemical activity. They can also interact with proteins and new peptides developed during the process and reduce their bioactive potential (Alam et al., 2016). 


\section{Conclusions}

The extrusion process showed different effects in all studied parameters of this work. Regarding organic acids evaluation, it was evident that extrusion conditions did not significantly affect these compounds. However, this food processing revealed a significant decrease in the tocopherols content and, in some cases, the complete absence of tocopherols isoforms. The percentage of legumes in the formulations was a variable that significantly affected the concentration of phenolic compounds since a higher amount of these compounds were found in the blends with a higher concentration of beans and carob fruit. In general, the extrusion process causes a decrease in the phenolic compounds content. Taking into account the bioactivity assays, mainly the cytotoxicity evaluation, the results showed some heterogeneity; the raw carob fruit, the commercial extruded rice and most of the extruded samples showed anti-proliferative potential, proving that the extrusion process increased the cytotoxic activity. The anti-inflammatory evaluation showed that this process did not significantly affect most of the samples, except for N-Ex 40.3, Ex 20.2, Ex 20.3 and Ex 40.2. For antimicrobial activity, most of the samples presented MIC values, ranging between 10 and $20 \mathrm{mg} / \mathrm{mL}$, or displayed an absence of this activity; therefore, they presented poor antimicrobial potential since the tested microorganisms were multi-resistant isolated clinical strains.

Regarding the initial hypothesis, we can conclude that rice, beans and carob fruit formulations are a great alternative for the development of new gluten-free snacks products in a market dominated mainly by cereals due to the presence of different bioactive compounds, which can give healthy benefits to the consumers.

\section{Acknowledgements}

The authors are grateful to the Foundation for Science and Technology (FCT, Portugal) and FEDER under Program PT2020 for financial support to CIMO (UID/AGR/00690/2019), L. Barros and R. Calhelha contracts. The authors are also grateful to FEDER-Interreg España-Portugal programme for financial support through the project 0377_Iberphenol_6_E, to the Spanish Ministry of Economy and Competitiveness (Project RTA2012-00042-C02) and INIA for the financial support of C. Arribas.

\section{Conflict of interest}

The authors declare they have no conflict of interest.

\section{References}

Aguilera, Y., Estrella, I., Benitez, V., Esteban, R. N., \& Martín-Cabrejas, M. A. (2011) Bioactive phenolic compounds and functional properties of dehydrated bean flours. Food Research International, 44, 774-780.

Alam, M., Kaur, J., Khaira, H., \& Gupta, K. (2016). Extrusion and extruded products: Changes in quality attributes as affected by extrusion process parameters: A review. Critical Reviews in Food Science and Nutrition, 56, 445-473.

Alves, G., Elizabeth, N., de Mejía, E. G., Vasconcelos, C. M., Bassinello, P. Z., \& Martino, H. S. D. (2016). Postharvest storage of carioca bean (Phaseolus vulgaris L.) did not impair inhibition of inflammation in lipopolysaccharide-induced human THP-1 macrophage-like cells. Journal of Functional Foods, 23, 154-166 Elsevier Ltd.

Alves, M. J., Ferreira, I. C. F. R., Martins, A., \& Pintado, M. (2012). Antimicrobial activity of wild mushroom extracts against clinical isolates resistant to different antibiotics. Journal of Applied Microbiology, 113, 466-475.

Amarowicz, R., Dykes, G. A., \& Pegg, R. B. (2008). Antibacterial activity of tannin constituents from Phaseolus vulgaris, Fagoypyrum esculentum, Corylus avellana and Juglans nigra. Fitoterapia, 79, 217-219.

Arribas, C., Cabellos, B., Cuadrado, C., Guillamón, E., \& Pedrosa, M. M. (2019). The effect of extrusion on the bioactive compounds and antioxidant capacity of novel glutenfree expanded products based on carob fruit, pea and rice blends. Innovative Food Science \& Emerging Technologies, 52, 100-107.

Arribas, C., Cabellos, B., Sánchez, C., Cuadrado, C., Guillamón, E. \& Pedrosa, M. M. (2017). The impact of extrusion on the nutritional composition, dietary fiber and in vitro digestibility of gluten-free snacks based on rice, pea and carob flour blends. Food and Function, 8(10), 3654-3663.

Bessada, S. M. F., Barreira, J. C. M., Barros, L., Ferreira, I. C. F. R., \& Oliveira, M. B. P. P.
(2016). Phenolic profile and antioxidant activity of Coleostephus myconis (L.) Rchb.f.: An underexploited and highly disseminated species. Industrial Crops and Products, 89, 45-51.

Boehning, A. L., Essien, S. A., Underwood, E. L., Dash, P. K., \& Boehning, D. (2018). Cell type-dependent effects of ellagic acid on cellular metabolism. Biomedicine \& Pharmacotherapy, 106, 411-418.

Boschin, G., \& Arnoldi, A. (2011). Legumes are valuable sources of tocopherols. Food Chemistry, 127, 1199-1203.

Buzzini, P., Arapitsas, P., Goretti, M., Branda, E., Turchetti, B., Pinelli, P., ... Romani, A. (2008). Antimicrobial and antiviral activity of hydrolysable tannins. Mini Reviews in Medicinal Chemistry, 8, 1179-1187.

Caleja, C., Barros, L., Antonio, A. L., Carocho, M., Oliveira, M. B. P. P., \& Ferreira, I. C. F. R. (2016). Fortification of yogurts with different antioxidant preservatives: A comparative study between natural and synthetic additives. Food Chemistry, 210, 262-268.

Cámara, M., Diez, C., Torija, M., \& Cano, M. P. (1994). HPLC determination of organic acids in pineapple juices and nectars. Zeitschrift Fur Lebensmittel-Untersuchung Und -Forschung, 198, 52-56.

Ciudad-Mulero, M., Barros, L., Fernandes, Â., Berrios, J. D. J., Cámara, M., Morales, P., Ferreira, I. C. F. R. (2018). Bioactive compounds and antioxidant capacity of extruded snack-type products developed from novel formulations of lentil and nutritional yeast flours. Food \& Function, 9(2), 819-829.

Correa, R. C. G., de Souza, A. H. P., Calhelha, R. C., Barros, L., Glamoclija, J., Sokovic, M., Ferreira, I. C. F. R. (2015). Bioactive formulations prepared from fruiting bodies and submerged culture mycelia of the Brazilian edible mushroom Pleurotus ostreatoroseus Singer. Food \& Function, 6, 2155-2164.

Delgado-Licon, E., Ayala, A. L. M., Rocha-Guzman, N. E., Gallegos-Infante, J.-A., AtienzoLazos, M., Drzewiecki, J., ... Gorinstein, S. (2009). Influence of extrusion on the bioactive compounds and the antioxidant capacity of the bean/corn mixtures. International Journal of Food Sciences and Nutrition, 60(6), 522-532.

Dias, M. I., Barros, L., Morales, P., Sánchez-Mata, M. C., Oliveira, M. B. P. P., \& Ferreira, I. C. F. R. (2015). Nutritional parameters of infusions and decoctions obtained from Fragaria vesca L. roots and vegetative parts. LWT - Food Science and Technology, 62 , 32-38.

Guimarães, R., Barros, L., Dueñas, M., Carvalho, A. M., Queiroz, M. J. R. P., SantosBuelga, C., \& Ferreira, I. C. F. R. (2013). Characterisation of phenolic compounds in wild fruits from Northeastern Portugal. Food Chemistry, 141, 3721-3730.

Kondo, S., Teongtip, R., Srichana, D., \& Itharat, A. (2015). Antimicrobial activity of rice bran extracts for diarrheal disease. Journal of the Medical Association of Thailand, 94, 7-8.

Kotrotsios, N., Christaki, E., Bonos, E., Florou-Paneri, P., \& Spais, A. B. (2011). Carobs in productive animal nutrition. Journal of the Hellenic Veterinary Medical Society, 62, 48-57.

Lachkar, N., Al-Sobarry, M. El, Hajaji, H., Lamkinsi, T., Lachkar, M., \& Alaoui, K. (2016). Anti-inflammatory and antioxidant effect of Ceratonia siliqua L. methanol barks extract. Journal of Chemical and Pharmaceutical Research, 3, 202-210.

Le Marchand, L. (2002). Cancer preventive effects of flavonoids-a review. Biomedicine Pharmacotherapy, 56, 269-301.

Lopez-Bucio, J., Nieto-Jacobo, M. F., Ramirez-Rodriguez, V. V., \& Herrera-Estrella, L. (2000). Organic acid metabolism in plants: From adaptive physiology to transgenic varieties for cultivation in extreme soils. Plant Science: An International Journal of Experimental Plant Biology, 160(1), 1-13.

Margier, M., Georgé, S., Hafnaoui, N., Remond, D., Nowicki, M., Du Chaffaut, L., Reboul, E. (2018). Nutritional composition and bioactive content of legumes: Characterization of pulses frequently consumed in France and effect of the cooking method. Nutrients, 10(11), 1668.

Matthaus, B., \& Özcan, M. M. (2011). Lipid evaluation of cultivated and wild carob (Ceratonia siliqua L.) seed oil growing in Turkey. Scientia Horticulturae, 130, 181-184.

Montoya-Rodríguez, A., Milán-Carrillo, J., Reyes-Moreno, C., \& de Mejía, E. (2015). Characterization of peptides found in unprocessed and extruded amaranth (Amaranthus hypochondriacus) pepsin/pancreatin hydrolysates. International Journal of Molecular Sciences, 16(12), 8536-8554.

Morales, P., Cebadera-Miranda, L., Cámara, R. M., Reis, F. S., Barros, L., Berrios, J. D. J., Cámara, M. (2015). Lentil flour formulations to develop new snack-type products by extrusion processing: Phytochemicals and antioxidant capacity. Journal of Functional Foods, 19, 537-544.

Papagiannopoulos, M., Wollseifen, H. R., Mellenthin, A., Haber, B., \& Galensa, R. (2004). Identification and quantification of polyphenols in carob fruits (Ceratonia siliqua L.) and derived products by HPLC-UV-ESI/MSn. Journal of Agricultural and Food Chemistry, 52, 3784-3791.

Pedrosa, M. M., Cuadrado, C., Burbano, C., Muzquiz, M., Cabellos, B., Olmedilla-Alonso, B., \& Asensio-Vegas, C. (2015). Effects of industrial canning on the proximate composition, bioactive compounds contents and nutritional profile of two Spanish common dry beans (Phaseolus vulgaris L.). Food Chemistry, 166, 68-75.

Pereira, C., Barros, L., \& Ferreira, I. C. F. R. (2015). A comparison of the nutritional contribution of thirty-nine aromatic plants used as condiments and/or herbal infusions. Plant Foods for Human Nutrition, 70, 176-183.

Rached, I., Barros, L., Fernandes, I. P., Santos-Buelga, C., Rodrigues, A. E., Ferchichi, A., Ferreira, I. C. F. R. (2016). Ceratonia siliqua L. hydroethanolic extract obtained by ultrasonication: Antioxidant activity, phenolic compounds profile and effects in yogurts functionalized with their free and microencapsulated forms. Food \& Function, 7, 1319-1328.

Rakib, E. M. H., Chicha, S., Abouricha, M., Alaoui, A. A., Bouli, M. H., \& Owen, R. W. (2010). Determination of phenolic composition of carob pods grown in different regions of Morocco. Journal of Natural Products, 3, 134-140.

Riaz, M. N., Asif, M., \& Ali, R. (2009). Stability of vitamins during extrusion. Critical 
Reviews in Food Science and Nutrition, 49, 361-368.

Rtibi, K., Jabri, M. A., Selmi, S., Souli, A., Sebai, H., El-Benna, J., ... Marzouki, L. (2015). Gastroprotective effect of carob (Ceratonia siliqua L.) against ethanol-induced oxidative stress in rat. BMC Complementary and Alternative Medicine, 15(1), 292.

Sammour, R. H., \& Abd-El-Raheem El- Shanshoury, R. (1992). Antimicrobial activity of legume seed proteins. Botanical Bulletin- Academia Sinica Taipei, 33, 185-190.

Seabra, R. M., Andrade, P. B., Valentão, P., Fernandes, E., Carvalho, F., \& Bastos, M. L. (2006). Anti-oxidant compounds extracted from several plant materials. Biomaterials from aquatic and terrestrial organisms. (NH) Jersey Plymouth, New Hampshire: Science Publishers-Enfield.

Sobral, F., Sampaio, A., Falcão, S., Queiroz, M. J. R. P., Calhelha, R. C., Vilas-Boas, M., \& Ferreira, I. C. F. R. (2016). Chemical characterization, antioxidant, anti-inflammatory and cytotoxic properties of bee venom collected in Northeast Portugal. Food and Chemical Toxicology, 94, 172-177.

Su, J. D. (1993). Studies of rapid determination of vitamin $\mathrm{E}$ and its application on natural foodstuffs. Journal of Food and Drug Analysis, 1, 61-70.

Sundarrajan, L. (2014). Effect of extrusion cooking on the nutritional properties of amaranth, quinoa, kañiwa and lupine. Helsinki. ISSN 0355-1180.

Valero-Muntildoz, M., Martín-Fernández, B., Ballesteros, S., Lahera, V., \& de las Heras, N. (2014). Carob pod insoluble fiber exerts anti-atherosclerotic effects in rabbits through sirtuin- 1 and peroxisome proliferator-activated receptor-c coactivator-1a. Journal of
Nutrition, 144, 1378-1384.

Varela, A., Guillamon, E., Cuadrado, C., Marzo, F., Burbano, C., Muzquiz, M., \& Pedrosa, M. (2007). Changes in nutritional active factors and protein in different legumes by extrusion/cooking. 6th European Conference of Grain Legumes Lisboa (Portugal).

Vichapong, J., Sookserm, M., Srijesdaruk, V., Swatsitang, P., \& Srijaranai, S. (2010). High performance liquid chromatographic analysis of phenolic compounds and their antioxidant activities in rice varieties. LWT - Food Science and Technology, 43, 1325-1330.

Xu, B., \& Chang, S. K. (2010). Phenolic substance characterization and chemical and cellbased antioxidant activities of 11 lentils grown in the Northern United States. Journal of Agricultural and Food Chemistry, 58, 1509-1517.

Yu, T., Ahn, H. M., Shen, T., Yoon, K., Jang, H.-J., Lee, Y. J., ... Cho, J. Y. (2011). Antiinflammatory activity of ethanol extract derived from Phaseolus angularis beans. Journal of Ethnopharmacology, 137(3), 1197-1206.

Zhang, J., Li, L., Kim, S. H., Hagerman, A. E., \& Lü, J. (2009). Anti-cancer, anti-diabetic and other pharmacologic and biological activities of penta-galloyl-glucose. Pharmaceutical Research, 26, 2066-2080.

Zhu, F., Du, B., \& Xu, B. (2018). Anti-inflammatory effects of phytochemicals from fruits, vegetables, and food legumes: A review. Critical Reviews in Food Science and Nutrition, $58,1260-1270$. 